\title{
ERRATUM
}

Edmund Haberstroh • Wolf-Martin Hoffmann

Reinhart Poprawe - Fahri Sari

\section{Laser transmission joining in microtechnology}

Published online: 7 July 2006

(c) Springer-Verlag 2006

\section{Microsyst Technol (2006) 12:632-639}

Unfortunately, an error occurred in the title of this article. The corrected title is shown above.

The online version of the original article can be found at http:// dx.doi.org/10.1007/s00542-006-0096-0

E. Haberstroh · W.-M. Hoffmann ( $\varangle)$

Institute of Plastics Processing at RWTH Aachen,

Pontstr. 49, 52062 Aachen, Germany

E-mail: hoffmann_w@ikv.rwth-aachen.de

Tel.: +49-241-8028363

Fax: +49-241-8092262

R. Poprawe $\cdot$ F. Sari $(\square)$

Fraunhofer Institute for Laser Technology,

Steinbachstrasse 15, 52074 Aachen, Germany

E-mail: fahri.sari@ilt.fraunhofer.de

Tel.: + 49-241-8906145

Fax: + 49-241-8906121 